\title{
Enhanced isoproturon mineralisation in a clay silt loam agricultural soil
}

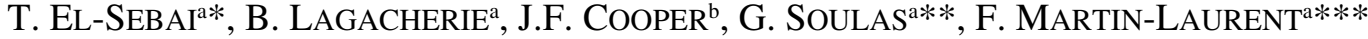 \\ ${ }^{\text {a }}$ UMR Microbiologie et Géochimie des Sols, INRA/Université de Bourgogne, 17 rue Sully, BP 86510, 21065 Dijon Cedex, France \\ LCBE, Centre de Phytopharmacie, Université de Perpignan, 58 avenue Paul, ALDUY, 66860 Perpignan Cedex, France
}

(Accepted 16 April 2004)

\begin{abstract}
C}$-ring-labelled isoproturon mineralisation was investigated in a French agricultural soil previously exposed to isoproturon. 50 different soil samples collected every $2 \mathrm{~m}$ along a transect of $100 \mathrm{~m}$ in length were treated one or two times with isoproturon under laboratory conditions and analysed by radiorespirometry. $94 \%$ of the soil samples showed a high ability to mineralise isoproturon with a relatively low variability in the cumulative percentage of mineralisation ranging from 30 to $51 \%$ of the initially added radioactivity for the samples treated once with the herbicide. About 45 to $67 \%$ of the initially added radioactivity was transformed into ${ }^{14} \mathrm{CO}_{2}$ in soil samples treated twice with isoproturon. Fifty-one to $30 \%$ of the radioactive pesticide formed bound residues 120 days after the first isoproturon treatment. The radioactive compound incorporated in the microbial biomass ranged from 3 to $4 \%$ of the initially added radioactivity. The methanol-extractable radioactivity was negligible and in the majority of soil samples no metabolites could be detected by high performance liquid chromatography analyses. However, in one soil sample showing low ability to mineralise isoproturon, the mono-demethyl isoproturon derivative represented about $12 \%$ of the methanol-extractable fraction. After the second isoproturon treatment, the rate of isoproturon mineralisation was enhanced in most soil samples and the number of soil samples showing a low isoproturon mineralisation capacity decreased. A significant relationship (correlation coefficient, 0.89) between the logarithm of the mineralisation rate (ln $\mathrm{k}$ ) and the soil $\mathrm{pH}$ was found, with a particularly strong positive effect on isoproturon mineralisation for $\mathrm{pH}>6.5$.
\end{abstract}

isoproturon / biodegradation / soil microflora

\section{INTRODUCTION}

Herbicides belonging to the family of substituted urea are extensively used in agriculture, particularly in France, where the annual consumption reached 4665 tons in 1998 (Tixier et al., 2002). These substances enter the plant via the roots and inhibit the photosynthesis (Ducruet, 1991). They are mainly employed to selectively control weeds in cereal cultures. Phenylurea herbicides are transformed in soil by dealkylation, followed by cleavage of the phenylurea bridge yielding aniline derivatives (Sorensen et al., 2003). These metabolites can form bound residues (Azam et al., 1988) or be condensed into the corresponding azobenzenes (Pieuchot et al., 1996). Hydroxylation of alkyl side chains and mineralisation of the phenyl ring have also been observed (Mudd et al., 1983; Lehr et al., 1996; Perrin-Ganier et al., 1996). Photodecomposition leads to demethylation and ring hydroxylation (Faure and Boule, 1997; Jirkovsky et al., 1997). Although the transformation mechanisms are very similar for all phenylureas, their transformation rates are quite dif- ferent, with $\mathrm{DT}_{50}$ varying from 10 to 150 days (Kidd and James, 1991; Sorensen et al., 2003).

Isoproturon [3-(-4 isopropylphenyl)-1,1-dimethylurea] is one of the phenylurea herbicides which is widely used for preand post-emergence control of annual grasses and broad-leaved weeds in spring and winter cereals (Fournier et al., 1975). Approximately 3300 tonnes were applied on 3 million hectares of agricultural land in the UK in 1997, making isoproturon the most widely used organic pesticide in this country. As a result of its intensive and repeated use as well as its properties (i.e. moderate persistence and relatively low adsorption), isoproturon is often detected in ground and surface water in Europe at levels exceeding the EU drinking water limit, fixed to $0.1 \mu \mathrm{g} \cdot \mathrm{L}^{-1}$ (Nitchke and Schussler, 1998; Spliid and Koppen, 1998; Stangroom et al., 1998). Ecotoxicological data suggest that isoproturon and some of its metabolites are harmful to aquatic invertebrates, freshwater algae and microbial activity (Mansour et al., 1999; Pérés et al., 1996; Remde and Traunspurger, 1994). Isoproturon and its metabolites such as azobenzene are

\footnotetext{
* Present address: NRC, Pests and plant protection, El-Tahrair street, Dokki - Cairo 12622, Egypt.

** Present address: UMR Oenologie-Ampéologie, Université Victor Segalen Bordeaux 2, 351 cours de la libération, 33405 Talence Cedex, France.

*** Corresponding author: fmartin@dijon.inra.fr
} 
Table I. Soil physico-chemicals properties determined from 50 soil samples collected from the transect (*: soil centrifuge moisture at $1000 \mathrm{~g}$; **: mMol. $100^{-1} g$ ). ${ }^{\$}$ : granulometries properties determined from sub-samples made of 10 soil samples. EH for equivalent humidity, OM for organic matter content and EC for exchangeable cations.

\begin{tabular}{|c|c|c|c|c|c|c|c|c|c|c|c|}
\hline & \multirow[t]{2}{*}{ Clay } & \multicolumn{2}{|c|}{ Silts } & \multicolumn{2}{|c|}{ Sand } & \multirow{2}{*}{$\begin{array}{c}\text { EH } \\
*\end{array}$} & \multirow[t]{2}{*}{$\mathrm{OM}$} & \multirow[t]{2}{*}{$\mathrm{N}$} & \multirow[t]{2}{*}{$\mathrm{C} / \mathrm{N}$} & \multirow[t]{2}{*}{$\mathrm{pH}$} & \multirow{2}{*}{$\begin{array}{l}\mathrm{EC} \\
* *\end{array}$} \\
\hline & & fine & coarse & fine & coarse & & & & & & \\
\hline & $\%$ & $\%$ & $\%$ & $\%$ & $\%$ & $\%$ & $\%$ & $\%$ & $\mathrm{AU}$ & $\mathrm{AU}$ & $\mathrm{AU}$ \\
\hline Higher value & & & & & & 21.6 & 29.90 & 2.1 & 9.45 & 7.8 & 29.90 \\
\hline Lower value & & & & & & 20.5 & 20.60 & 1.4 & 8.06 & 5.5 & 20.60 \\
\hline Mean value & 17.1 & 29.8 & 44.4 & 8.8 & 0.5 & 21.3 & 26.8 & 1.78 & 8.75 & 7.1 & 26.8 \\
\hline Standard error & 1.0 & 0.4 & 1.1 & 0.7 & 0.1 & 0.4 & 2.1 & 0.16 & 0.31 & 0.4 & 2.1 \\
\hline
\end{tabular}

also suspected of being carcinogenic (Behera and Bhunya, 1990; Hoshiya et al., 1993; Brown, 1999).

Microbial degradation is considered to be the primary mechanism for isoproturon dissipation from soil (Fournier et al., 1975; Mudd et al., 1983; Gaillardon and Sabar, 1994; Cox et al., 1996). Recently, Turnbull et al. (2001) have isolated an Arthrobacter sp. able to degrade phenylurea (chlorotoluron, diuron, isoproturon, linuron, monolinuron and monuron) in their respective aniline derivatives by hydrolysis of the urea side chain in the carbonyl group. Another bacterial strain, Sphingomonas sp. (strain SRS2), has been isolated by Sorensen et al. (2001). It initiates isoproturon metabolism by two successive Ndemethylations, followed by the cleavage of the urea side chain and finally, by the mineralisation of the phenyl structure.

Previous experiments have shown that accelerated degradation of isoproturon in soils can be induced by repeated application of the herbicide (Cox et al., 1996). Repeated application of some organic compounds such as diazinon, carbofuran, iprodione and vinclozolin, butylate, EPTC, alachlor, metolachlor, fenamiphos and ethoprophos has led to enhancing their breakdown, which can be so efficient that the pesticide may become ineffective (Sethunathan, 1971; Felsott et al., 1985; Walker and Brown, 1986; Dowler et al., 1987; Stirling et al., 1992; Karpouzas et al., 1999). However, bioavailability and physical parameters such as $\mathrm{pH}$ and soil type strongly influence the degradation rate of pesticides (Aislabie and Lloyd-Jones, 1995). A significant negative linear relationship $\left(\mathrm{r}^{2}, 0.746\right)$ between the DT50 values of isoproturon and the soil $\mathrm{pH}$ has previously been reported (Walker et al., 2001a, b).

Detailed examination of isoproturon persistence and movement in agricultural soil revealed that it is quite persistent in the environment, being degraded by up to $40 \%$ after 3 months (Nicholls et al., 1993; Harris et al., 1994). Examples of lack of efficacy have been reported in France (Yassir et al., 1999). The aim of the present study was to characterise accelerated biodegradation of isoproturon in soil samples collected from the field of Le Souich (France), yearly treated with this herbicide for the last 10 years and characterised by a significant weed infestation. Isoproturon mineralisation kinetics were determined from soil samples of Le Souich and modelled using the modified Gompertz model. The influence of soil physicochemical parameters such as $\mathrm{pH}$ on isoproturon mineralisation parameters resulting from the modelling of isoproturon mineralisation kinetics was estimated.

\section{MATERIALS AND METHODS}

\subsection{Soil}

The soil was collected in April 2002 from an agricultural field (0-10 cm layer) located in "le Souich" (50 13 '21"N; $02^{\circ} 21$ '22'E). 50 separate soil samples were collected every $2 \mathrm{~m}$ along a transect $100 \mathrm{~m}$ in length. This field was continuously cropped with winter wheat and treated with $1.8 \mathrm{~kg} \mathrm{ha}^{-1}$ of isoproturon [3-(4-isopropylphenyl)-1,1 dimethyl urea] over the last decade. The soil physicochemical characteristics are shown in Table I. The moisture content of each soil sample and the water holding capacity of one average mixed sample were estimated before beginning the experiment. Soil samples were stored at $4{ }^{\circ} \mathrm{C}$ until used.

\subsection{Isoproturon mineralisation}

Isoproturon (analytical grade purity $>99 \%$ ) was purchased from Riedel-de-Haen (Germany). ${ }^{14} \mathrm{C}$-labelled isoproturon (specific activity $666 \mathrm{MBq} / \mathrm{mmol}$; 99\% radiochemical purity) was purchased from Amersham-Life Science (United Kingdom). Two series of 50 soil samples ( $40 \mathrm{~g}$ equivalent dry weight) were treated with $1.5 \mathrm{mg}$ of isoproturon per $\mathrm{kg}$ of soil. ${ }^{14} \mathrm{C}$-isoproturon ( $2 \mathrm{kBq}$ per sample) was added to the two series. Soil samples were moistened to $100 \%$ of water holding capacity and incubated at $20 \pm 0.5{ }^{\circ} \mathrm{C}$ in the dark for 120 days in closed respirometer jars (Soulas, 1993). After 14 days of incubation, one of the two series of soil samples was treated again with ${ }^{14} \mathrm{C}$ labelled isoproturon as previously described. ${ }^{14} \mathrm{CO}_{2}$ resulting from mineralisation of ${ }^{14} \mathrm{C}$-labelled isoproturon was trapped in $5 \mathrm{~mL}$ of $0.2 \mathrm{M} \mathrm{NaOH}$ solution placed in the respirometer. $\mathrm{NaOH}$ traps were changed after $1,2,3,4,6,8,10,14,17,21$, $24,28,31,35,42,49$ and 63 days of incubation. They were analysed for radioactivity content by liquid scintillation counting using ACSII (Amersham) scintillation fluid. The modified Gompertz growth model $\left[\mathrm{y}=\left(\mathrm{ae}^{-\mathrm{e}(\mathrm{k}(\mathrm{t}-\mathrm{ti}))}+\mathrm{ct}\right)\right]$ was fitted to the isoproturon mineralisation data using Sigma Plot 4.0. Four parameters were determined: $a$, the plateau or maximum percentage of mineralisation $t i$, the abscissa of the inflexion point $k$, the mineralisation rate constant, and $c$, the rate of ${ }^{14} \mathrm{C}$ turnover due to late isoproturon mineralisation and/or microbial carbon turnover. 


\section{3. ${ }^{14} \mathrm{C}$-isoproturon residues.}

At the end of the incubation (120 days), all the samples of the first series were extracted as follows: aliquots ( $20 \mathrm{~g}$ dry soil equivalent) were extracted with $40 \mathrm{~mL}$ methanol under agitation $\left(350 \mathrm{rpm}, 16 \mathrm{~h}\right.$ at $20{ }^{\circ} \mathrm{C}$ in the dark). Samples were centrifuged for $15 \mathrm{~min}$ at $6000 \mathrm{~g}$. An aliquot $(1 \mathrm{~mL})$ of the supernatants was analysed for extracted radioactivity by liquid scintillation counting. The remaining supernatant was evaporated at $40{ }^{\circ} \mathrm{C}$ to dryness using a Sample Concentrator (Brinkman $\mathrm{SC} / 48)$. The dried residues were dissolved in $2 \mathrm{~mL}$ of acetonitrile (Chromasolv for HPLC gradient grade) and analysed by reverse phase high performance liquid chromatography using a LC Star system (Varian) equipped with a MicrosorbMV C18 column (length $25 \mathrm{~cm}$, internal diameter $4.6 \mathrm{~mm}$, Varian) using an acetonitrile-water $(75 / 25, \mathrm{~V} / \mathrm{V})$ solvent system delivered at a flow rate of $0.75 \mathrm{ml} \cdot \mathrm{min}^{-1}$. Isoproturon was detected at $240 \mathrm{~nm}$.

Quantitative determination of non-extractable radioactivity, mainly corresponding to the bound residues, was performed by combustion of $0.5 \mathrm{mg}$ of dried soil samples extracted with methanol under $\mathrm{O}_{2}$ flow at $900{ }^{\circ} \mathrm{C}$ for 4 min (Biological Oxydiser OX-500, EG\&G Instruments, France). The ${ }^{14} \mathrm{C}-\mathrm{CO}_{2}$ was trapped in $15 \mathrm{~mL}$ of mixture (Oxysolve $\mathrm{C}-400$ scintillate) and the radioactivity was determined by liquid scintillation counting.

\subsection{Incorporation of radioactivity in the soil microbial biomass}

The ${ }^{14} \mathrm{C}$ incorporated in the microbial biomass was determined using the fumigation-extraction method (Vance et al., 1987). For each soil sample, one aliquot (10 g dry soil equivalent) was fumigated overnight with ethanol-free chloroform vapours in a vacuum incubator. After fumigation, chloroform vapours were eliminated by 3 successive evacuations. A second aliquot of soil was left unfumigated. Organic carbon was extracted from both fumigated and unfumigated soil samples with potassium sulphate $(0.025 \mathrm{M} ; 50 \mathrm{~mL})$ by agitation on a rotary shaker for $45 \mathrm{~min}$. Extracts were filtered on Whatman GF/C paper and 3 to 4 drops of phosphoric acid were added. The radioactivity of the extracts was measured by liquid scintillation counting. The ${ }^{14} \mathrm{C}$ incorporated in the microbial biomass was determined using the formula: biomass ${ }^{14} \mathrm{C}=(\mathrm{dpm}$ fumigated extract - dpm unfumigated extract)/Kc. The Kc factor (0.37) was used to convert extractable carbon into biomasscarbon.

\section{RESULTS AND DISCUSSION}

\subsection{Isoproturon mineralisation kinetics}

The mineralisation kinetics of isoproturon were determined by quantifying ${ }^{14} \mathrm{CO}_{2}$ trapped in $\mathrm{NaOH}$ after $1,2,3,4,6,8$, $10,14,17,21,24,28,31,35,42,49$ and 63 days of incubation. The majority of soil samples treated once with isoproturon showed a high ability to mineralise isoproturon. These samples showed a relatively low variability in the cumulative percentage of mineralisation, which ranged from 15 to $60 \%$ of the initially added radioactivity after 14 days of incubation (Fig. 1,

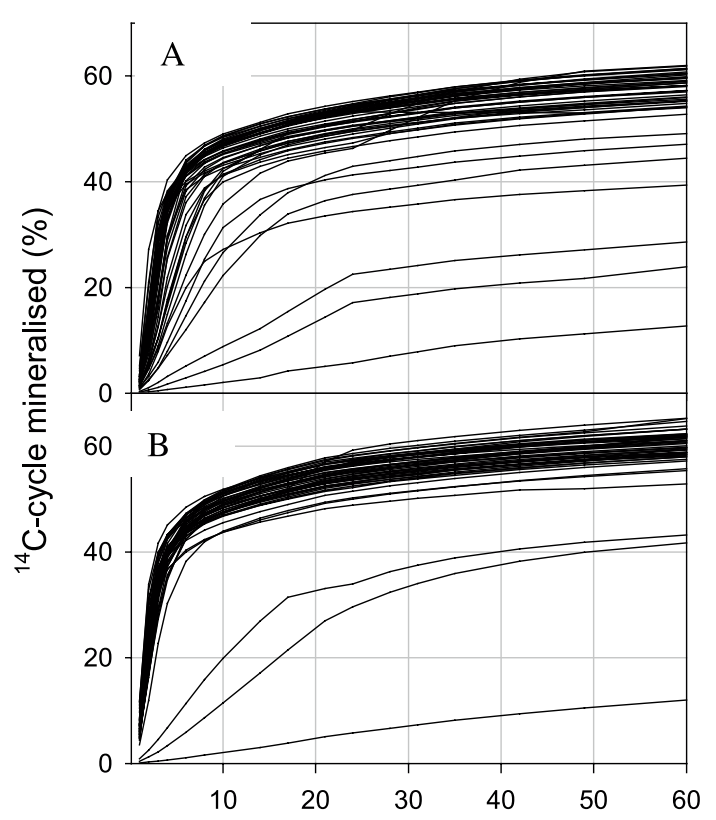

Figure 1. Kinetics of mineralisation of isoproturon determined for 50 soil samples collected from the field of Le Souich along a transect of $100 \mathrm{~m}$ in length, either treated once or twice with isoproturon under laboratory conditions.

panel A). Only three soil samples mineralised less than $20 \%$ of the initially added isoproturon after 14 days. Differences observed in isoproturon mineralisation may reflect the size of the isoproturon-degrading microbial communities initially present in the soil. According to the rate of mineralisation, soil samples could be separated into four categories for which the maximum rate of mineralisation was observed after (i) 2 , (ii) 2.5 , (iii) 4 and (iv) 5 days. After 120 days of incubation most of the soil samples exhibited cumulative percentages of mineralisation ranging from $50 \%$ to $70 \%$ of the initially added radioactivity. Only three samples mineralised less than $45 \%$ of the initially added isoproturon. The relatively low variability of isoproturon biodegradation may reflect a relatively low spatial heterogeneity of isoproturon-degrading microbes.

Most of the soil samples treated twice with isoproturon showed a maximum rate of mineralisation after 1.5 days of incubation while samples treated once exhibited maximal $\mathrm{k}$ values after only 2.5 days (Fig. 1, panel B). It suggests that the repeated application of isoproturon treatment to the soil enhanced its mineralisation rate. These results are in agreement with previous work reporting the isolation and the characterisation of Sphingomonas sp (SRS2), a bacterial strain able to mineralise isoproturon from an adapted experimental plot repeatedly treated with isoproturon (Sorensen et al., 2001, 2002).

Isoproturon mineralisation kinetics was fitted using the modified Gompertz model. The distribution within classes of the mineralisation rate constant (Fig. 2, panel A) and of the abscissa of the inflexion point (Fig. 2, panel B) revealed that under laboratory conditions two successive isoproturon treatments applied to the soil significantly modified its mineralisation. This observation may explain the decreased efficacy of 

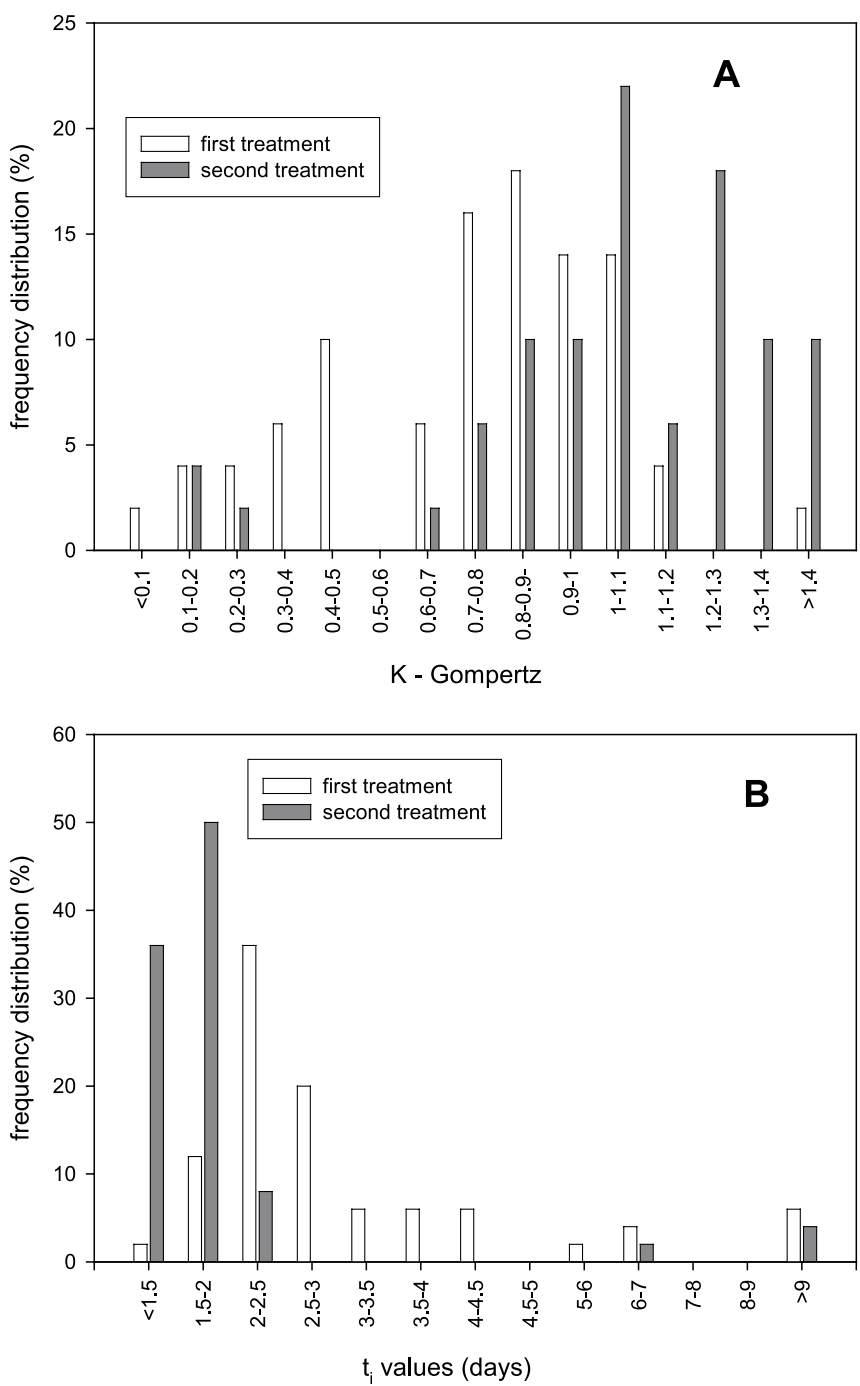

Figure 2. Frequency distributions of the isoproturon mineralisation rate constant $(\mathrm{k})$ determined from the modelling of isoproturon mineralisation kinetics of soil samples either treated once or twice with isoproturon under laboratory conditions.

isoproturon and the presence of weeds, such as foxtail (Alopecurus myosuroides Huds), reported by the farmer on this field plot. The modification of the frequency distribution of the isoproturon mineralisation kinetics parameters in response to repeated herbicide treatment revealed differences in isoproturon-degrading activity between samples, which may result from the properties of the isoproturon-degrading microbial communities.

It has previously been reported that the soil microflora of British and Danish agricultural soils adapted to isoproturon degradation in response to repeated application of isoproturon (Cox et al., 1996; Soulas et al., 1993). Our results suggest that repeated application of isoproturon on the field of Le Souich, continuously cropped with winter wheat over the last decade, contributed to the adaptation of soil microflora which became able to rapidly biodegrade this herbicide. In fact, the median

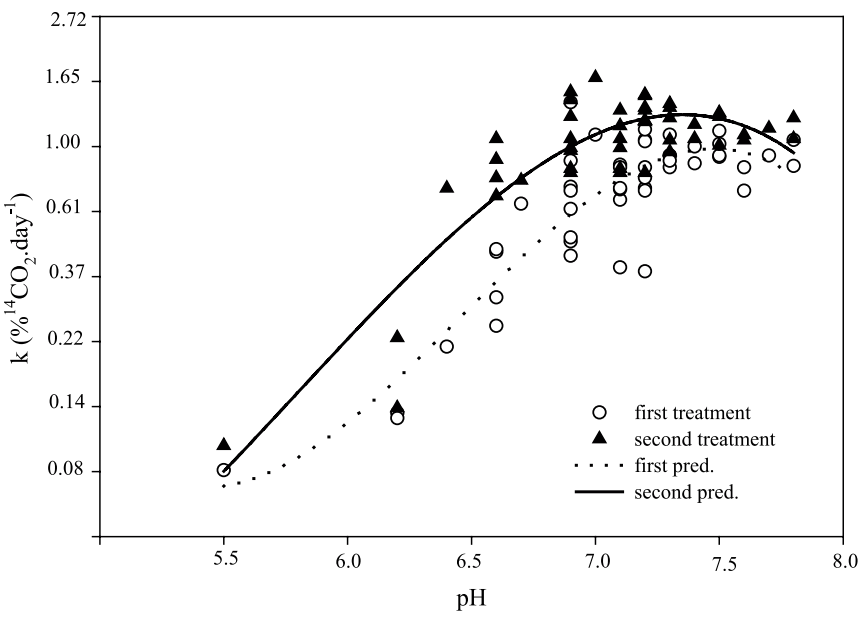

Figure 3. Evidence for the existence of a significant correlation between the soil $\mathrm{pH}$ and the logarithm of the mineralisation rate constant $(\mathrm{k})$ determined from the modelling of isoproturon mineralisation kinetics. First pred. for prediction obtained for soil samples treated once with isoproturon and second pred. for prediction obtained for soil samples treated twice with isoproturon.

frequency of the abscissa of the inflexion point observed in soil samples treated twice with isoproturon is almost 2 times lower than those treated only once. In addition, it is noteworthy that the median frequency of the mineralisation rate $(\mathrm{k})$ observed in soil samples treated twice with isoproturon is lower than those treated once. As it has been previously suggested, biodegradation is one of the major processes contributing to pesticides' dissipation of their phytotoxicity from soil (Cox et al., 1996; Fournier et al., 1975; Gaillardon and Sabar, 1994; Mudd et al., 1983). In previous studies, it has been shown that accelerated biodegradation of isoproturon often takes place in soil repeatedly treated with this herbicide (Cox et al., 1996; Soulas et al., 1993). Since the pioneering work of Audus (1949) reporting on 2,4-D and other phenoxyalcanoates, accelerated breakdown and an accompanying reduction in herbicide efficacy have been shown. As an example, decreased persistence of MCPA [(4-chloro-o-toly) oxy] acetic acid following two applications of MCPA has been described (Fryer and Kirkland, 1970). More recently, other chemicals such as carbofuran (Charnay and Fournier, 1994) and atrazine (Barriuso and Houot, 1996; Piutti et al., 2002) have been found to behave similarly. Another study revealed that soil microflora is also able to adapt to isoproturon biodegradation in response to prolonged periods of herbicide application.

Only very few soil samples did not respond to repeated application of isoproturon. In order to determine why they behaved differently, soil physicochemical characteristics ( $\mathrm{pH}$, organic matter, $\mathrm{N}, \mathrm{C} / \mathrm{N}$, equivalent humidity and exchangeable cations) were related to mineralisation potential estimated from the $\mathrm{k}$ value (i.e. mineralisation rate constant) using a polynomial regression procedure. Only one significant relationship between the mineralisation rate constant $(\mathrm{k})$ and the soil $\mathrm{pH}$ was observed with a relatively good correlation coefficient $\left(\mathrm{r}^{2}\right)$ of 0.89 in soil samples treated with isoproturon under laboratory conditions (Fig. 3). These results therefore indicate that soil $\mathrm{pH}$ 

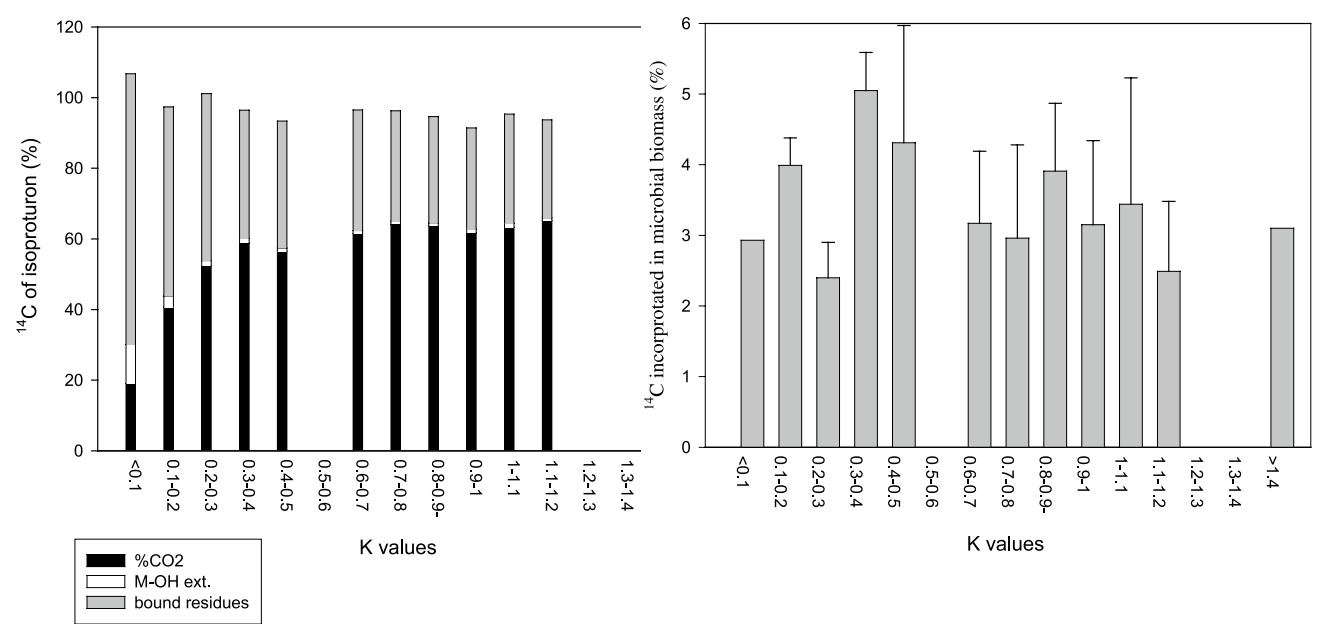

Figure 4. Distribution of ${ }^{14} \mathrm{C}$ in ${ }^{14} \mathrm{CO}_{2}$, microbial biomass, methanol extract and bound residues fractions in function of the mineralisation rate constant $(\mathrm{k})$ determined from the modelling of isoproturon mineralisation kinetics determined from soil samples treated once with this herbicide. $\mathrm{M}-\mathrm{OH}$ ext for methanol extract.

is a key physicochemical factor influencing the biodegradation rate of isoproturon. Studies of the fate of isoproturon in agricultural fields and contrasting soil types have revealed considerable spatial variability in degradation rates (Beck et al., 1996; Walker et al., 2001a, b). At two different sites in the United Kingdom, isoproturon half-life in soil was found to vary between 6 and 30 days, with the degradation rate varying according to the soil $\mathrm{pH}$. Recent studies demonstrated that the soil $\mathrm{pH}$ affected the ease of induction of growth-linked metabolism, with low degradation rates at low soil $\mathrm{pH}$ which is apparently linked to co-metabolic degradation of the compound (Bending et al., 2001). In more recent studies estimation of the size of isoproturon microbial communities based on Most Probable Number (MPN) counting showed that rapid biodegradation of isoproturon was associated with the proliferation of isoproturon-degrading micro-organisms (Bending et al., 2003). On the contrary, low biodegradation of isoproturon was either linked to a delay in its proliferation or to apparent co-metabolic degradation. In addition, an isoproturon-degrading isolate (Sphingomonas sp.) has been shown to have a narrow $\mathrm{pH}$ optimum (7 to 7.5) for optimal metabolism of isoproturon. Variation in the size of isoproturon-degrading microbial communities as well as soil $\mathrm{pH}$ could largely account for spatial variation of isoproturon degradation rates.

\subsection{Distribution of ${ }^{14} \mathrm{C}$ in different soil compartments}

The distribution of the ${ }^{14} \mathrm{C}$ in the different soil compartments was determined after 120 days of the incubation period (Fig. 4). ${ }^{14} \mathrm{C}$ reported as a function of the value of the isoproturon mineralisation (k) was distributed as follows: (i) 45 to $67 \%$ in ${ }^{14} \mathrm{CO}_{2}$, (ii) 0.5 to $10 \%$ in methanol extract, (iii) 30 to $51 \%$ in bound residues and (iv) 3 to $4 \%$ in microbial biomass. When a high amount of isoproturon was mineralised, only low amounts of radioactivity remained in the soil methanol extract and in the soil non-extractable fraction. The methanol-extractable radioactivity was very low in most soil samples analysed. Almost no metabolites could be detected by high performance liquid chromatography analyses. Only one soil sample showed a low ability to mineralise isoproturon. For this sample, the monodemethyl isoproturon derivative, the isoproturon and 4-isopropylaniline represented $12 \%, 5 \%$, and $4 \%$ of the methanol-extractable radioactivity. In addition, three unknown isoproturon metabolites eluted after 3.9, 7.0 and 8.3 min represented 52, 18 and 7\% of the methanol-extractable radioactivity, respectively. This set of data also indicated that the incorporation of ${ }^{14} \mathrm{C}$ in the microbial biomass did not vary significantly among the different soil samples (Fig. 4, panel B). These results suggest that the catabolic pathway specific for telluric bacterial communities adapted to isoproturon biodegradation is probably very similar in the different soil samples collected from the field of Le Souich. It suggests either the existence of a dominant degrading bacterial species or the existence of a catabolic pathway spread over the adapted isoproturon-degrading microflora.

\section{CONCLUSION}

The present study reports for the first time isoproturon biodegradation in a French clay silty loam agricultural soil treated with this herbicide for at least ten years, as it has previously been shown for a British agricultural soil (Cox et al., 1996). It confirms that repeated application of isoproturon induced the establishment of isoproturon-degrading microbial communities which are able to rapidly biodegrade this herbicide in soil samples in laboratory assays. The cumulative percentage of mineralisation reached up to $60 \%$ over a 40 -day incubation period. Isoproturon metabolites were non-detectable in most of the soil samples analysed, which all showed a high ability in isoproturon degradation. Soil $\mathrm{pH}$ was found to be positively 
correlated with the rate of isoproturon mineralisation. These observations are in agreement with recent studies suggesting that enhanced biodegradation of isoproturon in agricultural soils resulted from successive herbicide applications. This work also underlined the positive correlation between the mineralisation rate and soil $\mathrm{pH}$.

Acknowledgements: We would like to thank the Egyptian Ministry of Research for funding the PhD work of Talaat El Sebaï. We would also like to thank Dr Jacques Gasquez as well as Bayer CropSciences for helpful discussions.

\section{REFERENCES}

Aislabie J., Lloyd-Jones G. (1995) A review of bacterial degradation of pesticides, Aust. J. Soil Res. 33, 925-942.

Audus L.J. (1949) Biological detoxification of 2,4-D, Plant Soil 2, 31-35.

Azam F., Führ F., Mittelstaedt W. (1988) Fate of carbonyl- ${ }^{14} \mathrm{C}$ methabenzthiazuron in an arid region soil-effect of organic amendment, soil disturbance and fumigation, Plant Soil 107, 149-158.

Barriuso E., Houot S. (1996) Rapid mineralisation of the s-triazine ring of atrazine in soils in relation to soil management, Soil Biol. Biochem. 28,1341-1348.

Beck A.J., Harris G.L., Howse K.R., Johnston A.E., Jones K.C. (1996) Spatial and temporal variation of isoproturon residues and associated sorption/desorption parameters at the field scale, Chemosphere 33, 1283-1295.

Behera B.C., Bhunya S.P. (1990) Genotoxic effects of isoproturon (herbicide) as revealed by three mammalian in vivo mutagenic bioassays, Ind. J. Exp. Biol. 28, 862-867.

Bending G.D., Lincoln S.D., Sorensen S.R., Morgan J.A.W., Aamand J., Walker A. (2003) In-field spatial variability in the degradation of the phenyl-urea herbicide isoproturon is the results of interactions between degradative Sphingomonas spp. and soil pH, Appl. Environ. Microbiol. 69, 827-834.

Bending G.D., Shaw E., Walker A. (2001) Spatial heterogeneity in the metabolism and dynamics of isoproturon degrading microbial communities in soil, Biol. Fert. Soils 33, 484-489.

Brown A.E. (1999) Pesticides information Leaflet No. 33 Pesticides and Cancer, Entom. Dept., U. MD 1-14.

Charnay M.P., Fournier J.-C. (1994) Study of the relation between carbofuran degradation and microbial and physicochemical characteristics of some french soils, Pestic. Sci. 40, 207-216.

Cox L., Walker A., Welch S.J. (1996) Evidence for the enhanced biodegradation of isoproturon in soils, Pestic. Sci. 48, 253-260.

Dowler C., Marti L.R., Kvien C.S., Skipper H.D., Gooden D.T., Zublena J.P. (1987) Accelerated degradation potential of selected herbicides in the south eastern United States, Weed Tech. 1, 350-358.

Ducruet J.M. (1991) Les inhibiteurs du photosystème II, in: Scalla R. (Ed.), Les herbicides : mode d'action et principes d'utilisation, INRA Publishing, Paris, France, pp. 79-114

Faure V., Boule P. (1997) Phototransformation of linuron and chlorbromuron in aqueous solution, Pestic. Sci. 51, 413-418.

Felsott A.S., Steffey K.L., Levine E., Wilson J.G. (1985) Carbofuran persistence in soil and adult corn rootworm (Coleoptera: chrysomelidae) susceptibility: relationship to the control of damage by larvae, J. Econ. Entomol. 78, 45-52.

Fournier J.C., Soulas G., Catroux G. (1975) Dégradation microbienne de l'isoproturon dans des modèles de laboratoire, Chemosphere 4 207-214.
Fryer J.D., Kirkland K. (1970) Field experiments to investigate long-term effects of repeated application of MCPA, triallate, simazine and linuron: report after six years, Weed Res. 10, 133-138.

Gaillardon P., Sabar M. (1994) Changes in the concentration of isoproturon and its degradation products in soil and soil solution during incubation at two temperatures, Weed Res. 34, 243-251.

Harris G.L., Nicholls P.H., Bailey S.W., Howse K.R., Mason D.J. (1994) Factors influencing the loss of pesticides in drainage from a cracking clay soil, J. Hydrol. 27, 235-253.

Hoshiya T., Hasegawa R., Hakoi K., Cui L., Ogiso T., Cabral R., Ito N. (1993) Enhancement by nonmutagenic pesticides of GST-P positive hepatic foci development initiated with diethylnitosamine in the rat, Cancer Lett. 72, 59-64.

Jirkovsky J., Faure V., Boule P. (1997) Photolysis of diuron, Pestic. Sci. $50,42-52$.

Karpouzas D., Walker A., Froud-Willams R., Drennan D. (1999) Evidence for the enhanced biodegradation of ethoprophos and carbofuran in soils from Greece and UK, Pestic. Sci. 55, 301-311.

Kidd H., James D.R. (1991) The Agrochemicals Handbook, The Royal Society of Chemistry, Cambridge, England.

Lehr S., Glässgen W.E., Sandermann H., Besse F.J., Scheunert I. (1996) Metabolism of isoproturon in soils originating from different agricultural systems and in cultures of isolated soil bacteria, Int. J. Environ. Anal. Chem. 65, 231-243.

Mansour M., Feicht E.A., Behechti A., Schramm K.W., Kettrup A. (1999) Determination photostability of selected agrochemicals in water and soil, Chemosphere 39, 575-585.

Mudd P.J., Hance R.J., Wright S.J.L. (1983) The persistence and metabolism of isoproturon in soil, Weed Res. 23, 239-247.

Nicholls P.H., Evans A.A., Bromilow R.H. (1993) Persistence and leaching of isoproturon and mecoprop in the Brimstone farm plots, in: Proceedings Brighton Crop Protection Conference, Brighton, UK, pp. 849-854.

Nitchke L., Schussler W. (1998) Surface water pollution by herbicides from effluents of wastewater treatment plants, Chemosphere 36 $35-41$.

Pérés F., Florin D., Grollier T., Feurtet-Mazel A., Coste M., Ribeyre F., Ricard M., Boudou A. (1996) Effect of the phenylurea herbicide isoproturon on periphytic diatom communities in freshwater indoor microcosms, Environ. Pollut. 94, 141-152.

Perrin-Ganier C., Breuzin C., Portal J.-M., Schiavon M. (1996) Availability and persistence of isoproturon under field and laboratory conditions, Ecotoxicol. Environ. Saf. 35, 226-230.

Pieuchot M., Perrin-Garnier C., Portal J.-M., Schiavon M. (1996) Study on the mineralisation and degradation of isoproturon in three soils, Chemosphere 33, 467-478.

Piutti S., Hallet S., Rousseaux S., Philippot L., Soulas G., Martin-Laurent F. (2002) Accelerated mineralisation of atrazine in maize rhizosphere soil, Biol. Fert. Soils 36, 434-441.

Remde A., Traunspurger W. (1994) A method to assess the toxicity of pollutants on anaerobic microbial degradation activity in sediments, Environ. Toxicol. Water Qual. 9, 293-298.

Sethunathan N. (1971) Biodegradation of diazinon in paddy fields as a cause of its inefficiency for controlling brown plant hoppers in rice fields, Pest Article News Summaries (PANS) 17, 18-19.

Sorensen S.R., Ronen Z., Aamand J. (2001) Isolation from agricultural soil and characterization of a Sphingomonas sp. able to mineralize the phenylurea herbicide isoproturon, Appl. Environ. Microbiol. $67,5403-5409$.

Sorensen S.R., Ronen Z., Aamand J. (2002) Growth in co-culture stimulates metabolism of the phenylurea herbicide isoproturon by Sphingomonas sp. strain SRS2, Appl. Environ. Microbiol. 68, 3478-3485. 
Sorensen S.R., Bending G.D., Jacobsen C.S., Walker A., Aamand J. (2003) Minireview: Microbial degradation of isoproturon and related phenylurea herbicides in and below agricultural soils, FEMS Microbiol. Ecol. 45, 1-11.

Soulas G. (1993) Evidence for the existence of different physiological groups in the microbial community responsible for 2,4-D mineralisation in soil, Soil Biol. Biochem. 25, 443-449.

Spliid H.S., Koppen B. (1998) Occurrence of pesticides in Danish shallow groundwater, Chemosphere 37, 1307-1316.

Stangroom S.J., Collins C.D., Lester J.N. (1998) Sources of organic micro-pollutants to lowland rivers, Environ. Technol. 19, 643-666.

Stirling A.M., Stirling G.R., Macrae I.C. (1992) Microbial degradation of fenamiphos after repeated application to a tomato-growing soil, Nematologica 83, 245-254.

Tixier C., Sancelme M., Ait - Aissa S., Widehem P., Bonnemoy F., Cuer A., Truffaut N., Veschambre H. (2002) Biotransformation of phenylurea herbicides by a soil bacterial strain, Arthrobacter $s p$. N2 structure, ecotoxicity and fate of diuron metabolite with soil fungi, Chemosphere 46, 519-526.
Turnbull G.A., Cullington J.E., Walker A., Morgan J.A.W. (2001) Identification and characterisation of a diuron degrading bacterium, Biol. Fert. Soils 33, 472-476.

Vance E.D., Brookes P.C., Jenkinson D.S. (1987) An extraction method for measuring soil microbial biomass C, Soil Biol. Biochem. 19, 703-707.

Walker A., Brown P.A., Entwistle A.P. (1986) Enhanced degradation of iprodione and vinclozolin in soil, Pestic. Sci. 17, 183-193.

Walker A., Jurado-Exposito M., Bending G.D., Smith V.J.R. (2001a) Spatial variability in the degradation rate of isoproturon in soil, Environ. Pollut. 111, 407-415.

Walker A., Bromilow R.H., Nicholls P.H., Evans A.A., Smith V.J.R (2001b) Spatial variability in the degradation rates of isoproturon and chlorotoluron in a clay soil, Weed Res. 42, 39-44.

Yassir A., Lagacherie B., Houot S., Soulas G. (1999) Microbial aspects of atrazine biodegradation in relation to history of soil treatment, Pestic. Sci. 55, 799-809. 